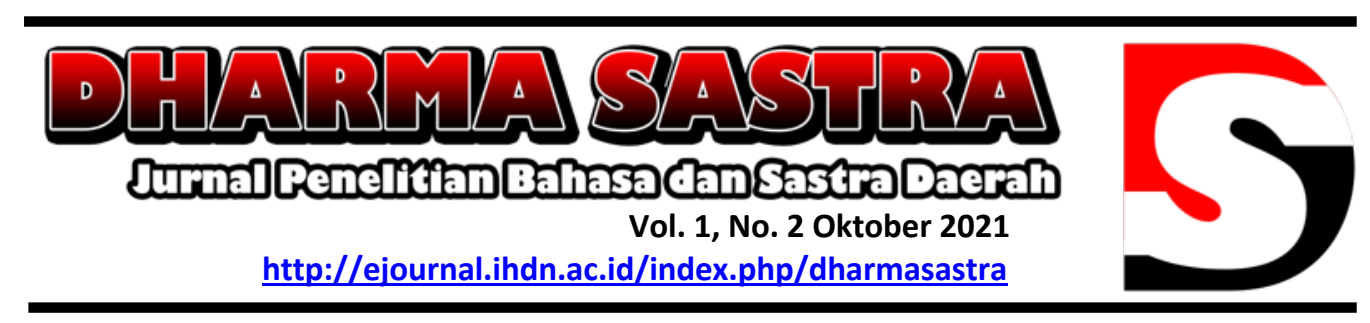

\title{
Kosakata Pinjaman dalam Pemakaian Bahasa Bali pada Mingguan Bali Orti \\ di Koran Bali Post Edisi Januari-Juni Tahun 2018
}

\author{
Ni Kadek Heni Sulyantari Dewi
}

SD Negeri 17 Dauh Puri, Email: henisulyantari89@gmail.com

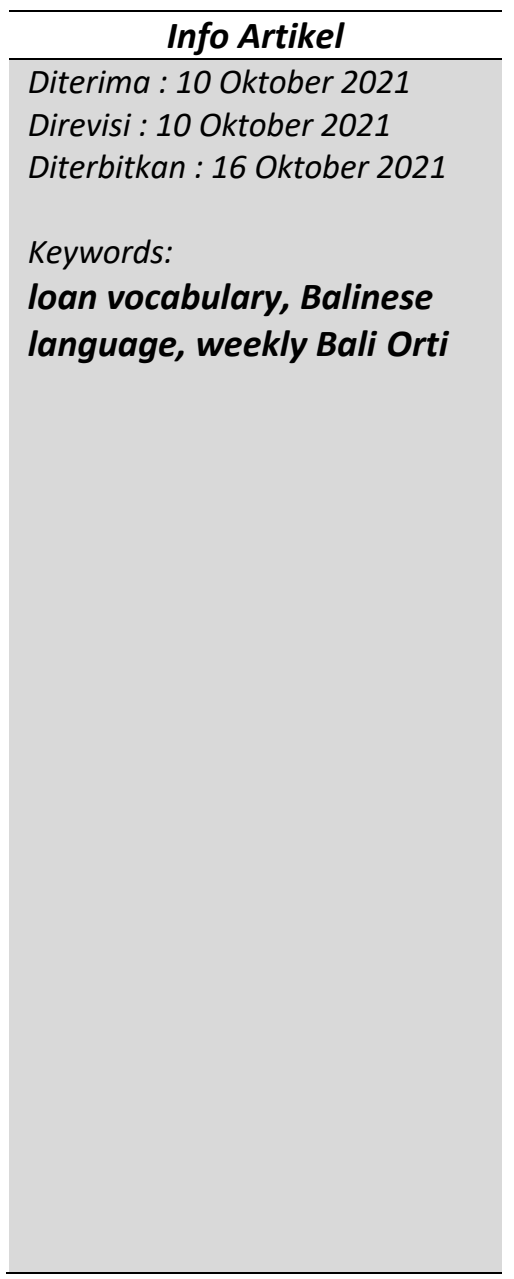

\begin{tabular}{l} 
Abstract \\
\hline Use of loan vocabulary from other language especially, \\
English in Balinese language become important to be \\
studied at this time. Some of the English loan vocabulary \\
actually equivqlences in Balinese language. The use of \\
loan vocabulary certainly has an impact in the attitude of \\
Balinese speaker. In this research the researcher \\
reviewing: 1) kinds of English the loan vocabulary in \\
Balinese language; 2) The factor causing loan vocabulary; \\
3) the attitude of Balinese speaker towards the loan \\
vocabulary. Relating to the kinds the loan vocabulary are \\
classified into two: 1) based on the levelof frequency and \\
extent of usage they are devided into two kinds, that is \\
speech loans for example: now, discontinue, net control, \\
and example language loan: outbond, modern; 2) based of \\
factor causing loan devided into two are loands need \\
example: now, spiritual, discontinue, instrument. \\
Furthermore, the factor that cause the occurrence of \\
English loan vocabulary are caused by three factors, such \\
as: 1) the borrower does not find an equvqlent word in the \\
Balinese language; 2) expressive power of lost word; 3) \\
difference in certain social values in the language involved. \\
Then relating to the attitude of the language of Balinese \\
speakers declarethem selves to be positive toward \\
Balinese language, but the people also received the entry \\
of loan vocabulary from English in the use of Balinese \\
language.
\end{tabular}




\section{Pendahuluan}

Mingguan Bali Orti adalah berita berbahasa Bali yang sudah diterbitkan sejak tahun 2005 sampai sekarang dalam bentuk rubrik pada halaman khusus di koran Bali Post. Penggunaan kosakata pinjaman dari bahasa lain, terutama bahasa Inggris dalam penulisan Bali Orti menjadi penting untuk dikaji saat ini. Beberapa kosakata pinjaman bahasa Inggris tersebut sebenarnya sudah memiliki padanan dalam bahasa Bali. Sejumlah kosakata bahasa Inggris ditemukan dalam pemakaian bahasa Bali pada Bali Orti seperti: Now, Outbond, modern, discontinue, net control, instrument, local genius, out of the box, world silent day, event, creator dan yang lain-lainnya.

Penggunaan kosakata pinjaman bahasa Inggris tersebut sebenarnya sudah memiliki padanan dalam bahasa Bali. Namun, dalam penulisannya digunakan istilah pinjaman. Misalnya kata Now pada frasa "generasi zaman now" (Bali Orti, 07 Januari 2018). istilah now bahasa Bali dipadankan dengan kata jani atau mangkin. Kemudian kata modern dipadankan dengan kata anyar. Penggunaan istilah bahasa Inggris dalam penulisan Bali Orti tersebut menandakan adanya faktor tertentu yang menyebabkan pawarta Bali Orti memakai kosakata pinjaman dalam tulisannya meskipun padanan kosakata tersebut sudah ada dalam bahasa Bali seperti disebutkan di atas. Hal tersebut menjadi kajian dalam penelitian ini yang berkaitan dengan faktor-faktor penyebab terjadinya kosakata pinjaman dalam pemakaian bahasa Bali pada penulisan Mingguan Bali Orti di koran Bali Post.

Pemakaian kosakata pinjaman seperti yang telah disebutkan di atas memiliki dampak di masyarakat berkaitan dengan sikap bahasa. Sikap bahasa yang ditunjukkan oleh masyarakat bisa saja sikap positif, negatif maupun netral. Perbedaan kebutuhan para penutur bahasa Bali akan menentukan dan mempengaruhi sikap bahasa masingmasing penutur. Fenomena ini selalu menarik untuk diteliti. Maka itu penelitian ini penting untuk dilakukan dengan fokus utama adalah kosakata pinjaman bahasa Inggris dalam pemakaian bahasa Bali pada Mingguan Bali Orti di koran Bali Post edisi JanuariJuni tahun 2018.

\section{Metode}

Penelitian ini adalah deskriptif kualitatif. Sumber data primer dalam penelitian ini adalah kosakata pinjaman bahasa Indonesia dan bahasa Inggris dalam pemakaian bahasa Bali pada berita rubrik Mingguan Bali Orti koran Bali Post edisi Januari sampai Juni 2018 yang diperoleh dari hasil membaca. Sedangkan data sekunder diperoleh dari hasil wawancara antara peneliti dengan beberapa informan yang telah ditentukan secara purposive sampling.

Data yang dikumpulkan berupa kata-kata, istilah, dan frasa dari bahasa Indonesia dan bahasa Inggris yang ditemukan pada Mingguan Bali Orti edisi Januari sampai Juni 2018. Data-data ini tergolong data primer. Data yang dikumpulkan diperoleh dari sumber data dengan pengamatan dan pencatatan langsung. Metode pengumpulan data dalam penelitian ini dilakukan dalam tiga tahap yaitu: 1) Observasi atau pengamatan, 2) Studi dokument, 3) Wawancara (Moelong dalam Muhammad, 2011: 33).

Setelah selesai tahap pengumpulan data maka dilanjutkan dengan melakukan analisis data. Dalam penelitian ini tahap analisis data dilakukan dengan dua metode yaitu metode agih dan metode padan (Haugen, 1951, 1971 dalam Muhammad, 2011: 
233-256). Penyajian hasil analisis yang digunakan adalah cara informal. Yaitu penyajian hasil dengan cara menguraikan atau memaparkan dengan kata-kata dalam bentuk paragraf-paragraf penjelasan.

\section{Pembahasanan}

1. Jenis-Jenis Kosakata Pinjaman dalam Pemakaian Bahasa Bali pada Mingguan Bali Orti

Jenis-jenis kosakata pinjaman dalam pemakaian bahasa Bali pada Mingguan Bali Orti di koran Bali Post edisi Januari-Juni tahun 2018 diklasifikasikan menjadi dua jenis yaitu : 1) Berdasarkan tingkat frekuensi dan luasnya pemakaian (Grosjean, 1982: 292) terbagi menjadi dua jenis pinjaman yaitu pinjaman tutur dan pinjaman bahasa 2) Berdasarkan faktor penyebab pinjaman (Grosjean, 1982 dan Weinreich, 1968) terbagi menjadi dua yaitu pinjaman perlu dan pinjaman tidak perlu.

a. Jenis Pinjaman Berdasarkan Tingkat Frekuensi dan Luasnya Pemakaian

1) Pinjaman Tutur

Kosakata pinjaman yang terdapat dalam Mingguan Bali Orti edisi Januari-Juni tahun 2018 ditemukan sebanyak dua puluh (20) kosakata maupun frasa yang dikategorikan sebagai pinjaman tutur yaitu: now, ion, infuse, discontinue, nét control, instrument, local genius, out of the box, creator, launching, world silent day, vernal equinox, event, delete, refresh, badminton, landscape, long life education, impersonal gods, dan personal gods.

Pinjaman tutur seperti disebutkan di atas, dalam penulisannya di Mingguan Bali Orti disajikan dalam bentuk kalimat langsung maupun tak langsung, dapat dilihat pada kutipan-kutipan berikut:

Bali Orti, 07 Januari 2018

(1) ... "Generasi Zaman Now" utawi "Generasi Z" sané kapanggihin sampun sayan nilarin mabasa Bali pinaka sarana mabebaosan saraina.

Bali Orti, 14 Januari 2018

(2) ...manut fisiologis wantah akéh madaging antuk ion taler "mineral alami"...

(3) Pateh sakadi toya murni utawi toya sané ketah kadagingin ring infuse ring rumah sakit.

Bali Orti, 14 Januari 2018

(4) parikrama nelebin sastra-sastra Bali olih para yowana kapanggihin discontinue utawi kamargiang ri kala jagi ngamargiang pacentokan kémanten,....

(5) Wénten taler angga komunitas sané dados "nét control" utawi sané jagi nabdabang sapasira angga sané prasida utawi dados mabebaosan mangda prasida trepti tur suaranipun nénten mapalu sangkaning samian sinarengan mabaosan utawi matembang 
Bali Orti, 04 Pebruari 2018

(6) Sinalih tunggil wangunnyané punika marupa seni tabuh utawi gambelan, seni marupa suara sané kamedalang saking makudangkudang piranti utawi instrument gambelan tradisional.

(7) Surya Pradnya malih maosang, parikrama punika majanten kamedalang antuk local genius utawi kawagedan krama irika.

Bali Orti, 18 Pebruari 2018

(8) Sakéwanten sané mangkin, piranti sakadi don lontar kapadonang antuk pikayunan miwah parikrama sané out of the box olih para seniman anyar, prasida ngamedalang makéh wangun pakaryan seni.

(9) ...manggalaning Sanggar Segitiga Sama Kaki sané taler creator saking barong lontar...

(10) Paletan kaping kalih wantah ngamecikang malih antuk sué kirang langkung tigang raina sané kamargiang wusan launching ring balé banjar Babakan, Canggu.

Bali Orti, 04 Maret 2018

(11) Nyepi punika kaanggén tetulad olih krama jagat utawi dura Negara antuk ngamedalang parikrama World Silent Day (WSD) sané ngaptiang mangda kramané mararian ajebos ngawigunayang montor taler maparikrama sios sané jagi ngamedalang andus...

(12) ...matan aine ngranjing ring Vernal Equinox utawi maitehan beneng ring "Khatulistiwa" sané ring sajeroning tattwa Hindu kaucap antuk Uttarayana.

(13) Parikrama raina sané mabinayan sareng rerainan siosan punika raris manados event nyabran warsa sané kajantosang taler kamargiang olih krama Hindu.

Bali Orti, 11 Maret 2018

(14) ...prasida nganggén komputer sané tatkala iwang prasida ka-delete kémanten, sinah teges ngamademang aksara nénten ja cupit sakadi ri kala nyurat lontar.

(15) ...jagi becik-becik nga-refresh raga miwah pikayunan saking sekancan pikobet sané kapanggihin...

Bali Orti, 13 Mei 2018

(16) Satios punika, oka pasangan I Gusti Agung Alit Yasa-Ni Nyoman Sudiani sané seneng mamaca, magamel miwah badminton puniki taler naen nyarengin pacentokan macecimpedan

Bali Orti, 20 Mei 2018

(17) Satios ngupapira kebun, anggané taler malajah makarya dekorasi taman, merangkai bunga miwah makarya landscape. 
Bali Orti, 27 Mei 2018

(18) Sakadi bebaosan long life education, sapunika taler ri kala malajahin basa Bali, kaplajahin salantang tuuh.

Bali Orti, 24 Juni 2018

(19) parikrama nyanjan miwah nedunang Ida Sang Hyang Widhi Wasa sané kahanannyané wantah Impersonal Gods utawi nénten marupa mangda dados Personal Gods antuk makatah rupan Ida malarapan antuk ngeréh.

Bentuk-bentuk yang dipinjam tersebut berupa kata maupun gabungan kata (frase) yang jarang dipakai dalam percakapan sehari-hari di masyarakat. Bahasa tersebut hanya digunakan oleh kalangan dan waktu tertentu saja, misalnya mahasiswa dan tenaga pengajar. Ketidak laziman penggunaan pinjaman tersebut dalam masyarakat, inilah yang menjadi ciri khas dari pinjaman tutur, yaitu pinjaman yang dalam tataran tutur saja dan jarang digunakan oleh masyarakat.

2) Pinjaman Bahasa

Pinjaman bahasa mengacu pada kosakata pinjaman yang sudah dikenal dan digunakan oleh masyarakat luas, atau tidak hanya digunakan oleh individu tertentu saja. Kosakata pinjaman dalam bahasa Bali pada Mingguan Bali Orti edisi Januari- Juni 2018 ditemukan sebanyak sebelas (11) kosakata maupun frasa yang dikategorikan sebagai pinjaman bahasa yaitu: outbond, modérn, enérgy, stakéholder, magnet, cultural, selfi, rolling door, stand, marching band, dan skill.

Berikut ini adalah kutipan-kutipan yang mengandung kosakata atau frasa pinjaman bahasa yaitu:

Bali Orti, 07 Januari 2018

(20) Penyuluh Bahasa Bali, minakadi ngajahin alit-alit malarapan kelompok belajar sané kamargiang ring soang-soang désa ring Bali utawi malajah basa Bali antuk parikrama minakadi outbond basa Bali...

(21) ... wénten sané kabaos antuk ranah tradisional miwah ranah modérn.

Bali Orti, 11 Pebruari 2018

(22) prasida nglanduhang pakarangan sané nedeng ngamedalang kasidhian utawi enérgy sané nglintang akéh tur patut pisan kadegdegang

Bali Orti, 01 April 2018

(23) Makasamian punika sampun kamargiang nganutin tata-titi sané sapatutnyané saha sampun matetimbang sareng stakéholder irika minakadi; Perbekel, BPD, LPM Désa Pergung miwah pamucuk krama taler Penyuluh Basa Bali ring Désa Pakraman Pergung.

Bali Orti, 13 Mei 2018

(24) Kaasrian palemahannyané sakadi magnet sané ngarad para wisatawané rauh ka genah inucap,... 
Bali Orti, 03 Juni 2018

(25) Punika prasida kabaosang dados "terjemahan cultural" saking tattwa Agama Hindu sané wikan tur pradnyan kamargiang olih para panglingsir Bali malarapan antuk pidabdab ring pakraman.

(26) Becik pinaka genah ngruruh inspirasi, napi malih sané seneng ring fotograf, pamekas selfi.

(27) Wéntuknyané sakadi rolling door sané patut kasorogang ka samping.

Bali Orti, 24 Juni 2018

(28) Stand ikan bakar madérét, majéjér ring sapanjang margi wewidangan Dusun Sukorejo. Krama sané rauh prasida ngrasayang sensasi bakar gurami ring stan sapanjang 300 meter punika.

(29) Taler karamé-nin antuk marching band miwah kasenian barongsai.

(30) "Indik panincapan skill krama sajeroning widang makarya olahan gurami, krama kaicén pelatihan memasak gurami

Pinjaman bahasa yang telah disebutkan di atas, merupakan pinjaman dengan frekuensi kemunculan yang tinggi. Hal tersebut disebabkan karena adanya faktor kebutuhan dan kebiasaan masyarakat satu yang kemudian berkembang, sehingga pinjaman tersebut digunakan oleh masyarakat luas.

b. Jenis Pinjaman Berdasarkan Faktor Penyebab Pinjaman

1) Pinjaman Perlu

Kosakata pinjaman dalam bahasa Bali di Mingguan Bali Orti di Koran Bali Post edisi Januari-Juni 2018 ditemukan sebanyak dua belas (12) kosakata maupun frasa yang dikategorikan sebagai pinjaman perlu diantaranya: outbond, infuse, net control, out of the box, launching, vernal equinox, stakéholder, magnet, landscape, selfi, rolling door, dan marching band.

Berikut sejumlah kutipan bahasa Bali yang mengandung kosakata pinjaman pada Mingguan Bali Orti dengan topik keagamaan dan budaya yaitu:

Bali Post, 07 Januari 2018

(25) Penyuluh Bahasa Bali, minakadi ngajahin alit-alit malarapan kelompok belajar sané kamargiang ring soang-soang désa ring Bali utawi malajah basa Bali antuk parikrama minakadi outbond basa Bali...

Bali Orti, 14 Januari 2018

(2) Pateh sakadi toya murni utawi toya sané ketah kadagingin ring infuse ring rumah sakit.

(6) Wénten taler angga komunitas sané dados "nét control" utawi sané jagi nabdabang sapasira angga sané prasida utawi dados mabebaosan mangda prasida trepti tur suaranipun nénten mapalu sangkaning samian sinarengan mabaosan utawi matembang. 
Bali Orti, 18 Pebruari 2018

(9) Sakéwanten sané mangkin, piranti sakadi don lontar kapadonang antuk pikayunan miwah parikrama sané out of the box olih para seniman anyar, prasida ngamedalang makéh wangun pakaryan seni.

(12) Paletan kaping kalih wantah ngamecikang malih antuk sué kirang langkung tigang raina sané kamargiang wusan launching ring balé banjar Babakan, Canggu.

Bali Orti, 04 Maret 2018

(14) ...matan aine ngranjing ring Vernal Equinox utawi maitehan beneng ring "Khatulistiwa" sané ring sajeroning tattwa Hindu kaucap antuk Uttarayana.

Bali Orti, 01 April 2018

(32) Makasamian punika sampun kamargiang nganutin tata-titi sané sapatutnyané saha sampun matetimbang sareng stakéholder irika minakadi; Perbekel, BPD, LPM Désa Pergung miwah pamucuk krama taler Penyuluh Basa Bali ring Désa Pakraman Pergung.

Bali Orti, 13 Mei 2018

(34) Kaasrian palemahannyané sakadi magnet sané ngarad para wisatawané rauh ka genah inucap,...

Bali Orti, 20 Mei 2018

(21)Satios ngupapira kebun, anggané taler malajah makarya dekorasi taman, merangkai bunga miwah makarya landscape.

Bali Orti, 03 Juni 2018

(37) Becik pinaka genah ngruruh inspirasi, napi malih sané seneng ring fotograf, pamekas selfi

Bali Orti, 03 Juni 2018

(38) Wéntuknyané sakadi rolling door sané patut kasorogang ka samping.

Bali Orti, 24 Juni 2018

(41) Taler karamé-nin antuk marching band miwah kasenian barongsai.

Sejumlah kosakata pinjaman dalam kutipan di atas, adalah kosakata yang memang perlu untuk dipinjam. Pinjaman tersebut muncul karena pawarta yakin bahwa tidak ada jalan lain kecuali meminjam kata yang hendak diujarkannya tersebut. Karena kata tersebut tidak ada atau tidak diketahui padanannya dalam bahasa Bali.

2) Pinjaman Tidak Perlu

Pinjaman tidak perlu seperti telah di bahas sebelumnya merupakan pinjaman yang memang tidak diperlukan karena sudah memiliki padanan dalam bahasa Bali. Namun, 
dalam penulisan Bali Orti kosakata pinjaman yang tergolong pinjaman tidak perlu tersebut masih ditemukan baik dalam bentuk kata maupun frase. Pinjaman yang dikategorikan sebagai pinjaman tidak perlu yaitu: now, modérn, discontinue, instrument, local genius, enérgy, creator, event, refresh, delete, badminton, long life education, cultural, impersonal gods, personal gods, stand, dan skill.

Berikut ini kutipan-kutipan yang mengandung pinjaman tidak perlu yaitu:

(1) ... "Generasi Zaman Now" utawi "Generasi Z" sané kapanggihin sampun sayan nilarin mabasa Bali pinaka sarana mabebaosan saraina (Bali Orti, 07 Januari 2018).

Dalam kutipan (1) kosakata pinjaman dimaksud adalah kata "Now". Now dalam bahasa Indonesia memiliki arti sekarang, saat ini (Marhiyanto \& Munir, 2000: 182) sedangkan dalam bahasa Bali diartikan jani, mangkin (Sutjaja, 2004: 396).

... wénten sané kabaos antuk ranah tradisional miwah ranah modérn (Bali Orti, 07 Januari 2018).

Dalam kutipan (26) kosakata pinjaman dimaksud adalah kata "modérn". Modern dalam bahasa Indonesia memiliki arti baru, model baru (Marhiyanto \& Munir, 2000: 171) dalam bahasa Bali memiliki arti sukla, anyar (Sutjaja, 2004: 33).

(5) "parikrama nelebin sastra-sastra Bali olih para yowana kapanggihin discontinue utawi kamargiang ri kala jagi ngamargiang pacentokan kémanten,.... (Bali Orti, 28 Januari 2018).

Dalam kutipan (5) kosakata pinjaman dimaksud adalah kata "discontinue". Discontinue dalam bahasa Indonesia memiliki arti berhenti, tidak berlanjut (Marhiyanto \& Munir, 2000: 85) dalam bahasa Bali memiliki arti mararian, masandekan (Sutjaja, 2004: 51).

(7) Sinalih tunggil wangunnyané punika marupa seni tabuh utawi gambelan, seni marupa suara sané kamedalang saking makudangkudang piranti utawi instrument gambelan tradisional (Bali Orti, 04 Pebruari 2018).

Dalam kutipan (7) kosakata pinjaman dimaksud adalah kata "instrument". Instrument dalam bahasa Indonesia memiliki arti alat, piagam (Marhiyanto \& Munir, 2000: 141) dalam bahasa Bali memiliki arti piranti, prabot (Sutjaja, 2004: 07).

(8) ...parikrama punika majanten kamedalang antuk local genius utawi kawagedan krama irika (Bali Orti, 11 Pebruari 2018).

Dalam kutipan (8) kosakata pinjaman dimaksud adalah kata "local genius". Local genius dalam bahasa Indonesia memiliki arti kearifan lokal (Marhiyanto \& Munir, 2000: .....) dalam bahasa Bali memiliki arti kawagedan krama (Sutjaja, 2004: ....). 
prasida nglanduhang pakarangan sané nedeng ngamedalang kasidhian utawi enérgy sané nglintang akéh tur patut pisan kadegdegang (Bali Orti, 11 Pebruari 2018).

Dalam kutipan (29) kosakata pinjaman dimaksud adalah kata "energy". Energy dalam bahasa Indonesia memiliki arti kekuatan (Marhiyanto \& Munir, 2000: .....) dalam bahasa Bali memiliki arti kasidian, taksu (Sutjaja, 2004: 215).

(10) ...manggalaning Sanggar Segitiga Sama Kaki sané taler creator saking barong lontar...(Bali Orti, 18 Pebruari 2018).

Dalam kutipan (10) kosakata pinjaman dimaksud adalah kata "creator". Creator dalam bahasa Indonesia memiliki arti pencipta (Marhiyanto \& Munir, 2000: 89) dalam bahasa Bali memiliki arti ngaé, ngardi, ngarya, ngwangun, pengawi (Sutjaja, 2004: 89).

(16) Parikrama raina sané mabinayan sareng rerainan siosan punika raris manados event nyabran warsa sané kajantosang taler kamargiang olih krama Hindu (Bali Orti, 04 Maret 2018).

Dalam kutipan (16) kosakata pinjaman dimaksud adalah kata "event". Event dalam bahasa Indonesia memiliki arti peristiwa, kejadian (Sutjaja, 2004: 344) dalam bahasa Bali memiliki arti parindikan, kawéntenan (Sutjaja, 2004: 344).

(18) ...jagi becik-becik nga-refresh raga miwah pikayunan saking sekancan pikobet sané kapanggihin...(Bali Orti, 11 Maret 2018).

Dalam kutipan (18) kosakata pinjaman dimaksud adalah kata "refresh". Refresh dalam bahasa Indonesia memiliki arti menyegarkan (Sutjaja, 2004: 394) dalam bahasa Bali memiliki arti seger, kenak (Sutjaja, 2004: 394).

(17) ...prasida nganggén komputer sané tatkala iwang prasida ka-delete kémanten, sinah teges ngamademang aksara nénten ja cupit sakadi ri kala nyurat lontar (Bali Orti, 11 Maret 2018).

Dalam kutipan (17) kosakata pinjaman dimaksud adalah kata "delete". Delete dalam bahasa Indonesia memiliki arti mencoret, menghapuskan, menghilangkan (Marhiyanto \& Munir, 2000: 95) dalam bahasa Bali memiliki arti puceh, ngicalang, ngilangang, ngusap (Sutjaja, 2004: 144).

(19) Satios punika, oka pasangan I Gusti Agung Alit Yasa-Ni Nyoman Sudiani sané seneng mamaca, magamel miwah badminton puniki taler naen nyarengin pacentokan macecimpedan (Bali Orti, 20 Mei 2018). 
Dalam kutipan (19) kosakata pinjaman dimaksud adalah kata "badminton". Badminton dalam bahasa Indonesia memiliki arti bulu tangkis (Marhiyanto \& Munir, 2000: 250) dalam bahasa Bali memiliki arti ...... (Sutjaja, 2004: 3).

(22) Sakadi bebaosan Long life education, sapunika taler ri kala malajahin basa Bali, kaplajahin salantang tuuh (Bali Orti, 27 Mei 2018)

Dalam kutipan (22) kosakata pinjaman dimaksud adalah pinjaman berbentuk frase yaitu "long life education". Longlife education dalam bahasa Indonesia memiliki arti belajar sepanjang hayat (Marhiyanto \& Munir, 2000: ....) dalam bahasa Bali memiliki arti malajah selantang tuuh (Sutjaja, 2004: ....).

(35) Punika prasida kabaosang dados "terjemahan cultural" saking tattwaAgama Hindu sané wikantur pradnyan kamargiang olih para panglingsir Bali malarapan antuk pidabdab ring pakraman (Bali Orti, 03 Juni 2018).

Dalam kutipan (36) kosakata pinjaman dimaksud adalah "cultural". Cultural dalam bahasa Indonesia memiliki arti kultural, mengkebudayakan, budaya (Marhiyanto \& Munir, 2000: 91) dalam bahasa Bali memiliki arti (Sutjaja, 2004: ....).

(23) parikrama nyanjan miwah nedunang Ida Sang Hyang Widhi Wasa sané kahanannyané wantah Impersonal Gods utawi nénten marupa mangda dados Personal Gods antuk makatah rupan Ida malarapan antuk ngeréh (Bali Orti, 24 Juni 2018)

Dalam kutipan (23) kosakata pinjaman dimaksud adalah pinjaman berbentuk frase yaitu "Impersonal Gods" dan "Personal Gods". Impersonal Gods dalam bahasa Indonesia memiliki arti Tuhan tanpa wujud, abstrak (Marhiyanto \& Munir, 2000: ...) dalam bahasa Bali memiliki arti sebel, ngeraja (Sutjaja, 2004: ....).

(39) Stand ikan bakar madérét, majéjér ring sapanjang margi wewidangan Dusun Sukorejo. Krama sané rauh prasida ngrasayang sensasi bakar gurami ring stan sapanjang 300 meter punika (Bali Orti, 24 Juni 2018).

Dalam kutipan (39) kosakata pinjaman dimaksud adalah "stand". Stand dalam bahasa Indonesia memiliki arti kios, kedai, perhentian (Marhiyanto \& Munir, 2000: 254) dalam bahasa Bali memiliki arti penggak, warung (Sutjaja, 2004: 185).

(42) "Indik panincapan skill krama sajeroning widang makarya olahan gurami, krama kaicén pelatihan memasak gurami"....(Bali Orti, 24 Juni 2018).

Dalam kutipan (42) kosakata pinjaman dimaksud adalah "skill". Skill dalam bahasa Indonesia memiliki arti keahlian, keterampilan, kecakapan (Marhiyanto \& Munir, 2000: 
243) dalam bahasa Bali memiliki arti midep, nawang, bisa, mampuh, nyidayang, prasida, sanggup, uning, wikan (Sutjaja, 2004: 64).

Beberapa contoh kosakata pinjaman tersebut di atas, dapat dicermati bahwa kosakata tersebut sudah memiliki padanan dalam bahasa Indonesia maupun bahasa Bali. Namun, dalam penulisan Bali Orti pawarta berita masih mempergunakan kata-kata tersebut dalam tulisannya.

\section{Faktor Penyebab Terjadinya Kosakata Pinjaman dalam Pemakaian Bahasa Bali pada Mingguan Bali Orti}

a. Peminjam Tidak Menemukan Padanan Kata dalam Bahasa Bali

Salah satu faktor yang melatarbelakangi terjadinya pinjaman adalah karena tidak ditemukannya padanan kata dalam bahasa Bali. Keadaan tersebut dipengaruhi oleh dua faktor yaitu: 1) keterbatasan wawasan kosakata bahasa Bali yang dimiliki peminjam, 2) adanya keterbatasan kosakata dalam bahasa Bali untuk mengacu pada hal, konsep, atau benda-benda tertentu (Grosjean, 1982).

I Wayan Agus Suryawan (wawancara, 20 Juli 2019) sebagai redaktur Bali Orti menyatakan pendapat yang sama dengan Grosjean, beliau menyatakan penggunaan pinjaman dari bahasa Inggris dalam bahasa Bali pada Mingguan Bali Orti koran Bali Post disebabkan oleh sejumlah istilah yang tidak dapat disampaikan dalam bahasa Bali karena dianggap tidak dapat mewakili makna yang ingin disampaikan oleh pawarta. Selain itu, tidak tersedianya padanan kata dalam bahasa Bali untuk menggantikan istilah bahasa Inggris, sehingga pawarta terpaksa memakai istilah bahasa Inggris tersebut. Misalnya dalam kutipan (25) berikut "Penyuluh Bahasa Bali, minakadi ngajahin alit-alit malarapan kelompok belajar sané kamargiang ring soang-soang désa ring Bali utawi malajah basa Bali antuk parikrama minakadi outbond basa Bali..." (Bali Orti, 07 Januari 2018).

Penggunaan kata outbond dalam kutipan tersebut oleh pawarta adalah untuk menyatakan istilah yang mengacu pada suatu rangkain acara yang di dalamnya mengandung unsur pembelajaran, rekreasi dan olahraga. Jika kata outbond tersebut digantikan dengan kata malali atau malilacita dalam bahasa Bali menurut hemat pawarta kata tersebut kurang tepat untuk menyatakan kegiatan yang dimaksud. Karena kata malali atau malilacita hanya mengandung makna kegiatan rekreasi atau hiburan semata yang tidak dapat merangkum kegiatan belajar, berolahraga maupun bermain.

\section{b. Daya Ekspresif Kata yang Hilang}

Sejumlah pinjaman dari bahasa Inggris dalam bahasa Bali pada Mingguan Bali Orti koran Bali Post disebabkan oleh faktor menurunya daya ekpresif kata yang menjadi padanan dalam bahasa Bali. Sebagai contoh dalam percakapan sehari-hari, kata modern tidak lagi menjadi bahasa yang asing didengar oleh masyarakat. Kata modern dalam bahasa Bali diartikan anyar, sukla (Sutjaja, 2004: 33). Seiring dengan perkembangan jaman penggunaan kata modern mulai merabah di masyarakat luas, baik masyarakat wilayah perkotaan maupun pedesaan.

Selain kata anyar, kata bahasa Bali seperti ngapus, ngusap, ngicalang yang berarti menghapus atau menghilangkan juga mulai tergantikan oleh kata delete. 
c. Perbedaan Nilai Sosial Tertentu pada Bahasa yang Dilibatkan

Pinjaman dari bahasa Inggris dalam bahasa Bali pada Mingguan Bali Orti koran Bali Post edisi Januari-Juni tahun 2018 ditemukan beberapa kata atau frase yang menunjukkan pretise sosial. Pinjaman tersebut ditulis berdasarkan informasi yang diperoleh dari narasumber. Terdapat beberapa narasumber yang memang menggunakan pinjaman tersebut dalam penyampaiannya. Sehingga dalam penulisannya pawarta mengutip langsung kata-kata yang disampaikan oleh narasumber. Misalnya seperti kata world silent day, discontinue, net control, out of the box, stakeholder, long life education, impersoanl gods, personal gods, dan skill.

Selain hal tersebut, yang menjadi perhatian adalah penggunaan Sor Singgih Basa Bali untuk menunjukkan status sosial dari narasumber. Ni Komang Sukma Wilatri (wawancara, 20 Juli 2019) menyampaikan dalam penulisan berita harus memperhatikan Sor Singgih Basa Bali untuk menunjukkan status sosial serta untuk menghormati narasumber.

\section{Sikap Bahasa Penutur Bahasa Bali Terhadap Kosakata Pinjaman dalam Pemakaian Bahasa Bali pada Mingguan Bali Orti}

a. Penulis atau Redaktur Mingguan Bali Orti

Ruscitadewi seorang tokoh penggagas terbentuknya Mingguan Bali Orti yang berasal dari kalangan pengawi sastra Bali atau pengarang. Berawal dari tahun 2004 dan terbit koran pertama pada tahun 2005. Beliau yang mengkordinir beberapa rekanrekannya yang juga sebagai pengawi sastra Bali untuk menyusun Mingguan Bali Orti yang bisa dinikmati oleh masyarakat Bali sampai saat ini. Terkait dengan sikap bahasa, beliau menyatakan sangat bangga terhadap bahasa Bali. Sebagai seorang pengasuh Mingguan Bali Orti, beliau menyatakan penggunaan kosakata pinjaman terutama dari bahasa Inggris sangat diperlukan dalam penulisan redaksi Bali Orti, karena memang diperlukan. Tentunya bahasa yang dipergunakan masih dalam konteks bahasa jurnalistik. Beliau menyatakan fungsi koran adalah media komunikasi, diharapkan penggunaan bahasa dalam tulisan dapat dicermati dan dipahami secara mudah. Sehingga tujuan komunikasi tersebut dapat diterima oleh masyarakat pembaca. Selain itu penggunaan kosakata pinjaman dari bahasa Inggris dalam bahasa Bali dapat menghilangkan kesan bahasa Bali monoton, namun berkembang sesuai dengan perkembangan zaman (Wawancara, 10 Juli 2019).

Ni Komang Sukma Wilatri dan I Wayan Agus Suryawan (wawancara, 20 Juli 2019) menyatakan penggunaan kosakata pinjaman akan memperkaya kosakata bahasa Bali. Penggunaan bahasa Bali tersebut didasari karena memang tidak ada padanannya dalam bahasa Bali. Sebagai redaktur Mingguan Bali Orti yang pasih berbahasa Bali menyatakan diri senang berbahasa Bali, bahasa Bali menunjukkan identitas sebagai orang Bali. Sesuai dengan pernyataan Jendra $(2011,19)$ menyatakan fungsi bahasa Bali adalah sebagai pelambang identitas orang Bali.

b. Masyarakat Umum

Sikap bangga berbahasa Bali juga disampaikan oleh informan pembaca Bali Orti dari kalangan masyarakat umum. Ni Ketut Alit Soma Armini (wawancara, 28 Juni 2019) menyatakan sikap positif terhadap bahasa Bali. Beliau merasa bangga terhadap bahasa 
Bali dan yakin bahasa Bali tidak akan punah karena masih tetap dipergunakan dalam setiap upacara yadnya dan tradisi masyarakat Bali. Sebagai pembaca Bali Orti, beliau menerima adanya penggunaan kosakata pinjaman dalam bahasa Bali. Penggunaan kosakata tersebut dianggap tidak merubah makna dari berita yang tersaji. Menurutnya pinjaman tersebut akan menambah wawasan pembaca serta dapat mejadi daya tarik untuk generasi muda agar mau membaca berita. Penggunaan kosakata bahasa Inggris yang sesuai menurutnya tidak akan menggeser keberadaan bahasa Bali.

\section{c. Tenaga Pendidik}

I Wayan Suardiana (wawancara, 02 Juli 2019) menyatakan diri bangga sebagai penutur bahasa Bali. Namun, beliau juga menyatakan tidak menolak masuknya kosakata pinjaman yang diserap dalam bahasa Bali. Beliau sebagai seorang tokoh akademisi yang juga pernah menjadi redaktur Bali Orti menjelaskan bahwa penggunaan kosakata pinjaman dalam penulisan Bali Orti tidak akan mengancam keberadaan bahasa Bali melainkan memperkaya kosakata bahasa Bali selama bahasa Bali tetap dihidupkan dalam bahasa tulis maupun lisan. Kutipan berikut adalah pernyataan dari Suardiana:

Jika bahasa Bali tidak meminjam istilah dari bahasa Inggris maupun bahasa asing lainnya maka bahasa Bali akan mandeg atau tidak bisa berkembang. Dalam pelestarian bahasa Bali, bahasa yang lama atau kuno harus tetap dihidupkan (Suardiana, wawancara 02 Juli 2019)

Suardiana juga menambahkan berbagai upaya yang dapat dilakukan untuk mempertahankan keberadaan bahasa Bali yaitu: 1) Bahasa Bali harus digunakan baik dalam bahasa lisan maupun tulis. 2) Tidak hanya menggunakan huruf latin, namun juga aksara Bali. 3) Membaca teks bahasa Bali huruf latin maupun aksara bali. serta 4) secara sadar diri mempertahankan yang lama, menggunakan yang sudah kita kuasai dan yang baru harus ditambahkan atau diserap sesuai kesepakatan dan kesepahaman masyarakat. mengharapkan masuknya usnur bahasa asing namun tidak melupakan bahasa ibu.

Pendapat yang senada juga disampaikan oleh I Gusti Nyoman Mastini (wawancara, 04 Juli 2019). Beliau menyatakan diri bangga sebagai penutur bahasa Bali yang memiliki bahasa dan aksara Bali. Sebagai seorang tenaga pendidik beliau terus berusaha untuk mengupayakan agar peserta didik mau dan mampu berbahasa Bali, tidak hanya bahasa lisan namun juga bahasa tulis. Beliau menyampaikan berbagai upaya telah dilakukan, khususnya di Jurusan Pendidikan Bahasa dan Sastra Agama Institut Hindu Dharma Negeri Denpasar untuk tetap menjaga kelestarian bahasa Bali. Upaya yang telah dilakukan adalah dengan mewajibkan mahasiswa untuk berbahasa Bali dalam interaksi dengan sesama, dengan dosen maupun antar warga kampus lainnya. Selain itu pada saat penyusunan tugas akhir skripsi juga mempergunakan bahasa Bali serta dalam pengajaran keterampilan berbahasa sangat ditekankan agar mahasiswa maupun dosen pengajar mampu berbahasa Bali dengan baik dan benar. Selain kegiatan belajar di dalam kelas, Jurusan Pendidikan Bahasa dan Sastra Agama juga memiliki UKM Keterampilan Berbahasa Bali (KBB) sebagai wadah mahasiswa untuk mengembangkan minat dan bakat berbahasa Bali. 


\section{Kesimpulan}

Kosakata pinjaman bahasa Inggris dalam pemakaian bahasa Bali pada Mingguan Bali Orti ditemukan sebanyak 44 kosakata bahasa Inggris. Terdapat beberapa penggunaan kata yang sama pada bulan yang berbeda sehingga cukup ditulis satu kosakata. Kosakata tersebut kemudian diklasifikasikan menjadi beberapa jenis yaitu: 1) Berdasarkan tingkat frekuensi dan luasnya pemakaian terbagi menjadi dua jenis pinjaman yaitu pinjaman tutur dan pinjaman bahasa 2) Berdasarkan faktor penyebab pinjaman terbagi menjadi dua yaitu pinjaman perlu dan pinjaman tidak perlu.

Penyebab terjadinya kosakata pinjaman dalam pemakaian bahasa Bali pada Mingguan Bali Orti dipengaruhi oleh tiga (3) faktor yaitu: 1) Peminjam tidak menemukan padanan kata dalam bahasa Bali. 2) Daya ekspresif kata yang hilang serta 3) Perbedaan nilai sosial tertentu pada bahasa yang dilibatkan.

Sikap bahasa yang ditunjukkan oleh masyarakat penutur bahasa Bali menyatakan diri bersikap positif terhadap bahasa Bali. Masyarakat menyatakan diri bangga berbahasa Bali. Namun juga tidak menolak adanya penggunaan kosakata pinjaman dalam bahasa Bali. Berdasarkan pendapat masyarakat masuknya kosakata pinjaman dalam bahasa Bali menjadi hal yang wajar di era modern saat ini. Masyarakat tidak menutup diri terhadap pengaruh bahasa asing terutama bahasa Inggris yang sudah masuk dalam kehidupan masyarakat. Masuknya kosakata pinjaman dinyatakan akan memperkaya kosakata bahasa Bali.

\section{Daftar Pustaka}

Arikunto, Suharsimi. 1989. Prosedur Penelitian Suatu Pendekatan Praktek. Jakarta: Bina Aksara.

Bloomfield, Leonard, 1933. Language, Terjemahan Sutikno, 1995. Bahasa. Jakarta: PT Gramedia.

Fishman, Joshua A.(ed). 1978. Advances in The Study of Societal Multilingualism. New York: Mouton.

Granoka, Ida Wayan Oka. 1996. Tata Bahasa Baku Bahasa Bali. Denpasar: Pemerintah Propinsi Daerah Tingkat I Bali Denpasar.

Grosjean, Francois. 1982. Life With Two Languages An Introduction to Bilingualism. United State: Harvard University Press.

Haugen, Einar. 1978. 'Bilingualism Language Context, and Immigrant Languages in The United State', dalam J.A. Fishman (ed). 1978. Advances in The Study of Societal Multilingualism. New York: Mouton.

Hornby, AS. 1987. Oxford Advanced Learner's Dictionary of Current English. Oxford: Oxford University Press.

Jendra, Wayan. 1991. Dasar-Dasar Sosiolinguistik. Denpasar: Ikayana.

Jendra, I Made Iwan Indrawan. 2001. 'Kosataka Bahasa Inggris dalam Pemakian Bahasa Indonesia pada Majalah dan Tabloid Remaja' (Tesis). Fakultas Sastra, Universitas Udayana.

Jendra, I Made Iwan Indrawan. 2011. Sosiologi Bahasa Bali. Denpasar: Vidia. 
Marcellino, M. 1998. 'Penyerapan Unsur Bahasa Asing dalam Pers', dalam bahasa Indonesia Menjelang Tahun 2000 Risalah Kongres bahasa Indonesia VI--Jakarta: Pusat Pembinaan dan Pengembangan Bahasa.

Marhiyanto \& Munir. 2000. Kamus Lengkap Inggris-Indonesia, Indonesia- Inggris: CV. Gitamedia Press

Marzuki, 1991. Metodologi Riset. Yogyakarta: PrasetyaWidya Pratama.

Mc Mahon, Steve. 1995. Understanding Languages Change. Cambridge: Cambridge University Press.

Muhammad. 2011. Metode Penelitian Bahasa. Jogjakarta: Ar-Ruzz Media.

Nababan, P.W.J.1984. Sosiolinguistik: Sebuah Pengantar. Jakarta: PT Gramedia.

Pateda, Mansoer dan Pulubuhu, Yennie. 1987. Unsur Serapan dalam Bahasa Indonesia dan Pengajarannya. Ende: Nusa Indah.

Pateda, Mansoer. 1987. Sosiolinguistik. Bandung: Angkasa.

Sudaryanto. 1993. Metode dan Aneka Tehnik Analisis Bahasa. Yogyakarta: Duta Wacana University Press.

Suhardi, Basuki. 1996.Sikap Bahasa. Depok: Fakultas Sastra Universitas Indonesia.

Sukendra, I Nyoman. 1996. 'Kedwibahasaan Generasi Muda pada Masyarakat Desa dan Kota di Bali' (tesis). Denpasar: Fakultas Sastra, Universitas Udayana.

Sumadiria, AS Haris. 2005. Jurnalistik Indonesia Menulis Berita dan Featur Panduan Praktis Jurnalis Profesional. Bandung: Simbiosa Rekatama Media.

Sumarsono. 1985. Pengantar Sosiolinguistik. Singaraja: IKIP Singaraja.

Sutjaja, I Gusti Made. 2007. Practical Balinese-English English-Balinese Dictionary: LotusWidya Sari.

Sutjaja, I Gusti Made. 2004. Kamus Indonesia Inggris Bali. Denpasar: Universitas Udayana.

TIM Penyusun. 2014. Kamus Besar Bahasa Indonesia Pusat Bahasa Edisi Keempat. Jakarta: PT. Gramedia Pustaka Utama.

TIM Redaksi. 2018. Bali Orti. Denpasar: Bali Post.

Tinggen, I Nengah. 1986. Sor Singgih Basa Bali Istilah Indonesia-Bali. Singaraja: Rhika Dewata. 